\title{
Spatial and temporal evolution of an experimental debris flow, exhibiting coupled fluid and particulate phases
}

\author{
C. M. Chalk ${ }^{1}$ (1) J. Peakall ${ }^{2} \cdot$ G. Keevil $\left.\right|^{2} \cdot$ R. Fuentes $^{3}$
}

Received: 9 November 2020 / Accepted: 3 June 2021 / Published online: 30 June 2021

(c) The Author(s) 2021

\begin{abstract}
The internal behaviour of debris flows provides fundamental insight into the mechanics responsible for their motion. We provide robust velocity data within a small-scale experimental debris flow, consisting of the instantaneous release of a granular material along a rectangular flume, inclined at $31^{\circ}$. The results show a unique layered transition from a collisional, turbulent front to a non-fluctuating viscous-type flow body, exhibiting strong fluid-particulate coupling. This is the first time that the internal dynamics have been documented within the full architecture of a developing experimental debris flow, from the head to the tail.
\end{abstract}

Keywords Debris flows · Flume experiments · Particle image velocimetry $\cdot$ Two-phase flow

\section{Introduction}

A debris flow is a gravity-driven flow in which the dynamics are governed by a coupled interaction between solid and fluid phases [17]. There are numerous ways in which debris flows are triggered, although they are usually associated with slope failure. Once triggered, debris flows develop a well-documented 'head-body" architecture $[17,46,48]$. The head is typically dry and contains the largest particles (e.g. rocks and boulders), while the body consists of smaller solid particles suspended in a viscous fluid. The combination of the solid and fluid forces at play enables debris flows to travel long distances at rapid rates [6], with potentially devastating consequences (e.g. $[5,38,42])$. Hence, it is crucial to gain a complete understanding of debris flow development in order to predict their behaviour.

C. M. Chalk

c.m.chalk@liverpool.ac.uk

1 Department of Earth, Ocean and Ecological Sciences, University of Liverpool, Liverpool, UK

2 School of Earth and Environment, University of Leeds, Leeds, UK

3 Institute of Geomechanics and Underground Technology, RWTH Aachen, Aachen, Germany
Over the years, debris flows have been the focus of a considerable amount of research, from both an analytical $[17,20,46]$ and experimental perspective $[3,10,15,21$, $23,29,45]$. Although real physical conditions can never be exactly represented, experimental debris flows allow for the investigation of key flow parameters in a controlled environment. While large scale experiments have the benefit of being directly comparable to real events [19], they are expensive, time consuming and complicated to execute. On the other hand, small scale gravity-driven flows have the advantage of being simple and repeatable, and are capable of reproducing some real debris flow features (e.g. the presence of a distinct granular head and fluidised body region). The main advantage of small scale debris flow experiments is the possibility of observing the internal flow dynamics. Image processing techniques can be applied to snapshots of the internal flow in order to produce internal velocity profiles. This information provides crucial insight on the mechanical and rheological behaviour of the flowing material $[28,34,48]$.

In the pioneering work of Armanini et al. [3], internal velocity profiles were calculated within a series of steady state water-granular flume experiments. The distinct shape of the velocity profiles for different experimental parameters lead to the definition of four different granular flow regimes that are relevant to debris flow bodies-immature, mature, plug flow and solid bed flow. These definitions 
have been frequently used to classify experimental debris flows conducted in more recent years [26, 28, 41]. Experimental debris flows are also often classified by directly comparing the internal velocity profiles with analytical profiles that are derived from simplified mathematical models with an assumed rheology [4]. This simple comparison can reveal whether the flow is dominated by granular or viscous-type behaviour [26, 28, 41]. It is important to note that analytical velocity profiles are derived from steady flow conditions. As a consequence, analytical internal profiles may only represent well-developed debris flow bodies, where the flow is steady. The internal flow behaviour in transient regions-i.e. the head, and the head-body transition region-cannot be described with analytical velocity profiles. Therefore experimental observation of the flow in transient debris flow regions is essential for a deeper understanding of debris flow dynamics overall. However, these regions are dominated by granular collisions, and if enough fluid is present in the flow, turbulent fluid [7], which makes them difficult to observe and analyse in experiments. As a result, the majority of experimental research into the internal dynamics of debris flows is focused on the body region. While such analyses provide valuable insight into the dynamics of the body of the debris flow, they cannot tell the whole story. To truly understand how debris flows evolve, it's essential to understand the internal mechanics within the full flow architecture.

The aim of this paper is to provide insight into the internal behaviour of debris flows, with a particular focus on the development from a transient head to a steady flow body. For this purpose, we present a descriptive analysis of the spatial and temporal internal evolution of an experimental debris flow. The experiments consisted of the dam break release of a water-granular mixture along an inclined flume. We applied Particle Image Velocimetry (PIV) to snapshots of the flow to produce internal velocity profiles in different regions. From this data, we discovered a unique two-layer transition from a transient and turbulent flow front, to a steady and viscous-type flow body. In addition to furthering the understanding of the internal mechanics of debris flows, the experimental data that we present are ideal for the validation and development of numerical models of water-granular flows.

The remainder of this paper is structured as follows. The experimental methodology is detailed in Sect. 2. The PIV velocity data are presented in Sect. 3, with a detailed discussion on the internal flow profiles-particularly in the transient flow development stage. We also compare our velocity profiles within the flow body to results presented in the literature. The key findings of this investigation are summarised in Sect. 4.

\section{Experimental methodology}

A mixture of water and granular material was manually released from behind a lock gate in a rectangular flume with dimensions $1.9 \times 0.2 \times 0.1 \mathrm{~m}$, at an inclination of $31^{\circ}$ (see Fig. 1a). This angle of inclination corresponds to that of the United States Geological Survey debris flow flume [21], and enables a rapid flow propagation. The mixture consisted of $2.177 \mathrm{~kg}$ of granular material and 1.51 of water, resulting in a total volume of $0.0026775 \mathrm{~m}^{3}$, with an initial solid volume fraction of $\phi_{s}=0.44$ and a bulk density of $\rho=1373 \mathrm{~kg} \mathrm{~m}^{-3}$. At the beginning of each experimental run, the granular material was placed behind a lock gate with a cross-sectional area in the shape of a trapezoid, occupying a volume of $0.0017255 \mathrm{~m}^{3}$. Subsequently, 1.51 of water was added slowly to minimise the disturbance to the top of the granular material. Due to its porosity, the granular material was rapidly saturated fully (see Fig. 1b). The granular material was multicoloured, crushed, glass grit with an angular shape, to represent natural granular material. The particle size distribution is shown in Fig. 2. The mean particle size is $d_{50}=0.917 \mathrm{~mm}$ ( $d_{x}$ denotes the percentage $x$ passing by area). The coefficient of uniformity $C_{U}=d_{60} / d_{10}$ represents the particle size variety, where $d_{60}=1 \mathrm{~mm}, d_{10}=0.1928 \mathrm{~mm}$ and $C_{U}=5$ (to the nearest integer). This particle size distribution is representative of some materials in the field that experience flow-type failures [33]. A thin, one-grain, layer of the same granular material was permanently fixed onto the flume bed to generate roughness which would produce a no-slip flow.

Shear box tests were conducted, for normal stress values of $30 \mathrm{kPa}, 60 \mathrm{kPa}, 100 \mathrm{kPa}$ and $130 \mathrm{kPa}$, to determine the internal friction angle of the granular material. The results are provided in Fig. 3. The samples were inspected after completion of the tests and no particle crushing was observed. The granular material showed a zero cohesion and an internal friction angle of $39^{\circ}$. The shear modulus of the material can be approximated as the gradient of the strain-stress curve before the peak values. This was found to be approximately $2.66 \times 10^{5} \mathrm{~Pa}$.

To check for repeatability, the experiment was performed three times. To observe the propagation of the flow, a high speed camera was positioned with its centre $1.098 \mathrm{~m}$ downstream from the lock gate, with the front of the lens $0.19 \mathrm{~m}$ from the flume. The camera is a Vision Research, Miro M120 Colour, with a Zeiss, $50 \mathrm{~mm}$ F1.4 ZF2 Planar lens. Upon release of the lock gate, and coeval triggering of the high speed camera, the mixture propagated downstream along the length of the flume and onto the run-out area. In order to capture the rapid flow dynamics, the images were taken at a rate of 1200 frames per second, with an exposure 


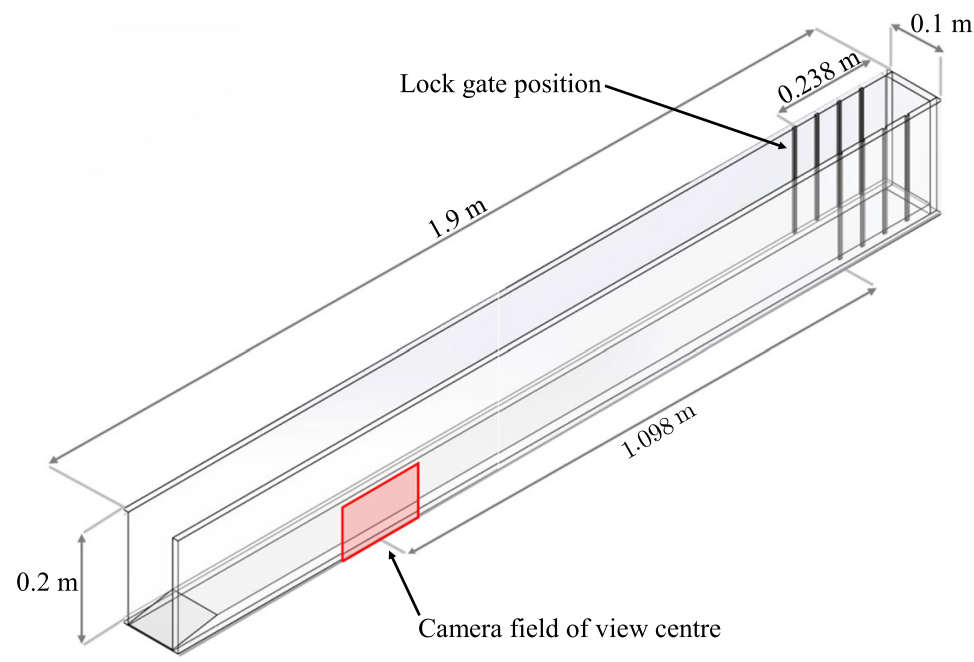

(a)

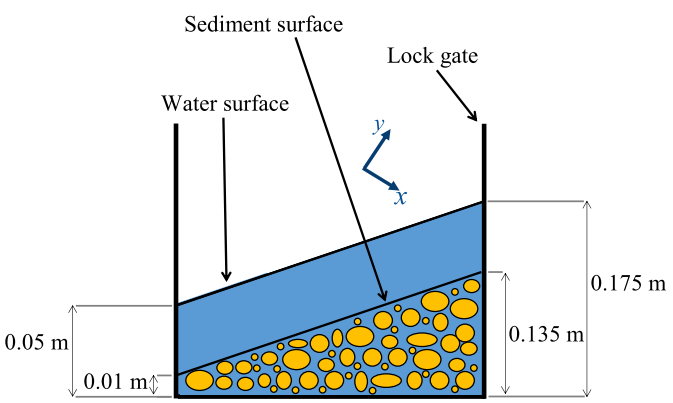

(b)

Fig. 1 Experimental set-up: a A schematic depiction of the flume, $\mathbf{b}$ The initial placement of the water-granular mixture behind the lock gate. In a the red rectangle denotes the camera field of view, with dimensions $0.0427 \times 0.0267 \mathrm{~m}^{2}$

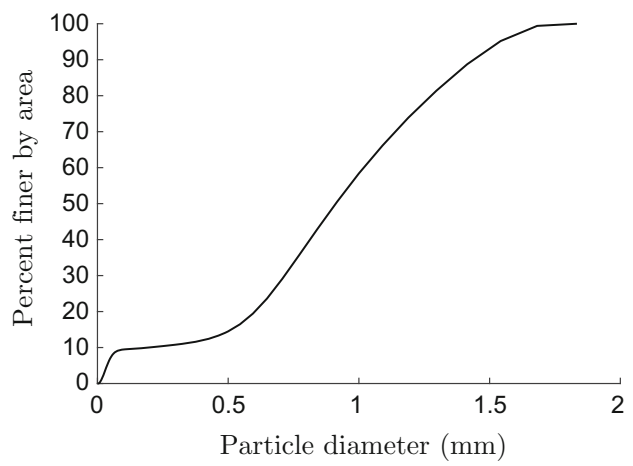

Fig. 2 Particle size distribution for the glass grit

time of $200 \mu$ s and a resolution of $1280 \times 800$ pixels. This short exposure time required the addition of extra lighting to obtain a suitable image quality. For this, two Nila LED lights (model Zaila) were placed on either side of the

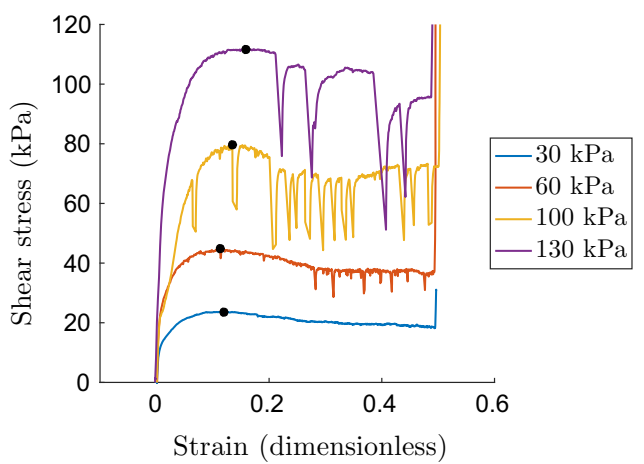

(a) camera, and one NanGuang LED light (model CN-60F) was positioned above it. The three lights were directed to optimise the light conditions in front of the camera. A photograph of the experimental set-up is shown in Fig. 4.

\subsection{Particle image velocimetry}

A PIV processing method was applied to the images obtained with the high speed camera. This is an experimental technique used within fluid and soil dynamics, where instantaneous velocity fields are determined by tracking the displacements of individual particles, or groups of particles, within a flow [1, 2, 39, 49]. An extensive description of the PIV method can be found in Adrian and Westerweel [2].

The image frames were processed using the DynamicStudio image processing software to obtain the velocity

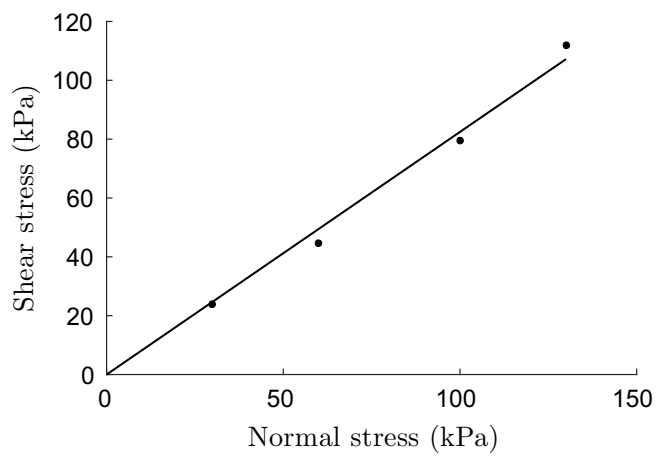

(b)

Fig. 3 Shear box test data: a Stress-strain relationship, b yield surface 


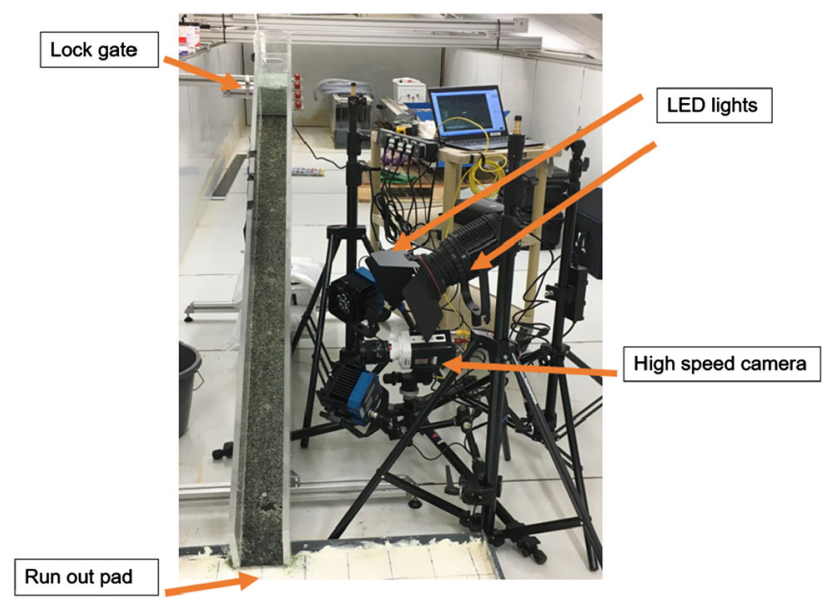

Fig. 4 A photograph of the experimental set-up just prior to flow initiation. The set-up consists of an acrylic channel with a roughened bed, that runs out onto a broader surface (at the bottom of the picture). A high speed camera and multiple LED lamps are used to visualise the flow

vectors. The 'Adaptive PIV' option was utilised within DynamicStudio, which automatically adjusts the interrogation area at each frame according to the local particle densities and velocity gradients. This requires the definition of the minimum and maximum values of interrogation areas, which were defined as $32 \times 32$ and $64 \times 64$ pixels, respectively. The reader is referred to the DynamicStudio user manual for further details on the adaptive PIV method [9]. No particle seeding was required to identify particles since the multicoloured granular material is easily identified without them [49].

Time averaged velocity profiles were obtained by averaging the velocity vectors over 30 successive frames, corresponding to a time interval of $0.025 \mathrm{~s}$. The initial flow time $(t=0)$ was defined to be when the front of the flow first reached the field of view of the camera, and the frames were cropped so that the first frame corresponds to $t=0$. For each considered flow time, the velocities were averaged over the 30 surrounding frames. For example, the velocities at the 60th frame $(t=0.05 \mathrm{~s})$ were time averaged by averaging over frames $45-75$.

\subsection{Collisional versus non-fluctuating behaviour}

The PIV data can be used to distinguish transient regions from the rest of the flow by considering deviations of velocity. This technique was applied by Paleo Cageao [34] to distinguish the collisional from the non-fluctuating regions of a small-scale experimental debris flow of a water and glass sphere mixture. Collisional flow is dominated by fluctuating granular collisions and turbulent fluid, and represents the behaviour that is typical of debris flow heads $[4,24]$. Non-fluctuating regions do not exhibit fluctuating granular collisions, and behave as a steady shear flow. In the current work, we adopt this technique to quantify regions of the evolving experimental flow.

To distinguish between collisional and non-fluctuating flow, Paleo Cageao [34] utilised the standard deviation $\bar{e}$ of the velocity from the local average, within that interval:

$\bar{e}=\sqrt{\frac{\sum_{i=1}^{N}\left(u_{x i}-\bar{u}_{x}\right)^{2}}{N-1}}$,

where $\bar{u}_{x}$ is the average velocity over $N$ frames (calculated at a single point), and $u_{x}^{\prime}$ is the instantaneous velocity. Low values of standard deviation equate to small variations in instantaneous velocity from the local mean, indicating nonfluctuating behaviour. Conversely, a high standard deviation demonstrates that the average velocity profile is not representative of the overall behaviour within the interval, as it is rapidly changing (corresponding to collisional behaviour). In the experiments of Paleo Cageao [34], velocity deviations of $\bar{e} \leq 0.15 \mathrm{~m} \mathrm{~s}^{-1}$ are assumed to represent non-fluctuating behaviour, while collisional behaviour is characterised by a standard deviation higher than this. Here, we also consider velocity deviations as a percentage of the average velocity, as opposed to an arbitrary cut-off point. It should be noted that Paleo Cageao [34] used the technique described above to remove the noisy, collisional data from their analysis, and focus only on the non-fluctuating regime. In our case, we use it to precisely locate the areas where both types of flow occur.

\section{Results and discussion}

\subsection{Flow description}

Once released from the lock gate, the water-granular mixture remained always fully saturated and propagated downstream, reaching maximum front velocities in the range of $1-1.2 \mathrm{~m} \mathrm{~s}^{-1}$. The main bulk of the flow deposited onto the run-out area, although a thin layer of the granular material (of approximately one particle thickness) was deposited along the bed of the flume.

Snapshots of the propagating mixture captured with the high speed camera are provided in Fig. 5, with the averaged velocity vectors obtained from the PIV analysis superimposed. The front part of the flow consists of a dilute and turbulent mixture. This region is shown at times $t=$ $0.035 \mathrm{~s}$ and $t=0.07 \mathrm{~s}$ where the entire mixture is evidently collisional as the PIV velocity vectors exhibit random and fluctuating behaviour throughout the majority of the flow depth. Following this, between $t=0.3 \mathrm{~s}$ to $t=0.6 \mathrm{~s}$, the height of the flow increases and a thin, upper layer of water (with a very low content of single grains) covers the 

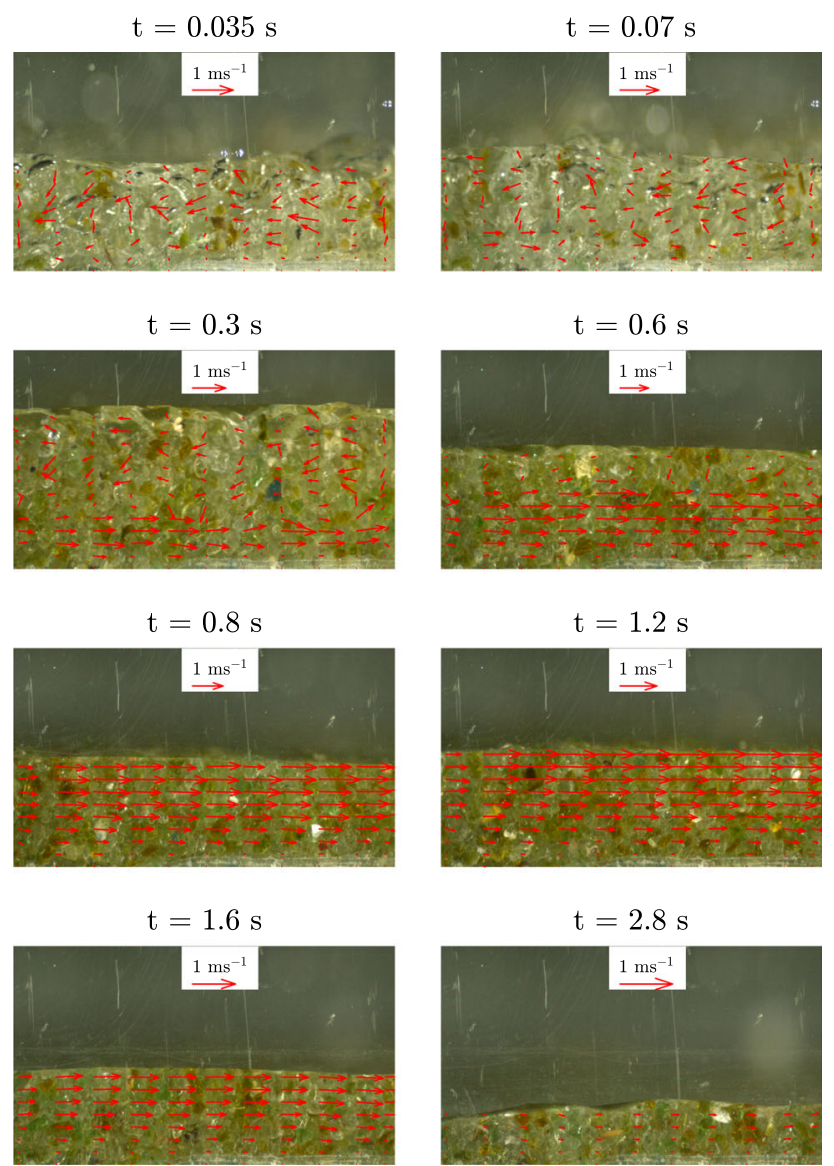

Fig. 5 Snapshots of the propagating water-granular mixture for Run 1 of the experimental flow, with the overlaid time-averaged PIV velocity vectors. The area of the camera field of view has been cropped to $0.0427 \times 0.02 \mathrm{~m}^{2}$

granular-water mixture. At the same time, the velocity vectors also show two distinct layers: a bottom layer with a uniform downstream velocity field, and an upper layer with noisy velocity vectors. As the material continues to flow downstream, the distinction of the two separate layers becomes less clear (see $t=0.8 \mathrm{~s}$ ), and the material continues to propagate as a uniform mixture with a constant height and a uniform velocity field. After approximately $1.4 \mathrm{~s}$, the flow gradually decreases in height as the material velocity decreases until the tail reaches the observation window. The mixture comes to a complete rest after $3 \mathrm{~s}$. Note that a very thin, watery layer is present at the flow surface for its duration.

The velocity vectors in Fig. 5 suggest the presence of two distinct flow regions, corresponding to the noisy and the smooth velocity vectors. We consider the deviations of velocity to quantify collisional and non-fluctuating flow regions. Following Paleo Cageao [34], we first consider a cut-off velocity value of $\bar{e}=0.15 \mathrm{~m} \mathrm{~s}^{-1}$. Figure 6 shows the results of this approach. However, in this paper we adopt a different approach in which we consider the deviations of velocity as a percentage of the local average velocity at each time frame. Contour plots of the standard deviation as a percentage are provided in Fig. 7 for Run 1, which is calculated as $100 \times \bar{e} / \bar{u}_{x}$. The upper limit of the contour scale is defined as $50 \%$, which was selected by trial and error as a suitable definition to differentiate between the two types of behaviour. The yellow regions in Fig. 7 correspond to areas of the flow that have a standard deviation that is greater than $50 \%$ of the local time-averaged velocity, and are here assumed to be collisional. Comparing Figs. 6 and 7 , the collisional flow is represented by the blue regions in both methods, and shows good agreement.

We can see from Fig. 7 that the experimental flow transforms from being purely collisional to non-fluctuating, with a layered transition at $t=0.6 \mathrm{~s}$ and $t=0.8 \mathrm{~s}$. The same overall behaviour is captured in Fig. 6. Collisional behaviour is exhibited throughout the depth of the flow at $t=0.035 \mathrm{~s}, t=0.07 \mathrm{~s}$ and $t=0.3 \mathrm{~s}$. At $t=0.6 \mathrm{~s}$, a nonfluctuating layer with a thickness of approximately $5 \mathrm{~mm}$ has developed. The height of this layer increases with time, and by $t=1.2 \mathrm{~s}$ the majority of the flow is uniform and non-fluctuating. In terms of the debris flow architecture, the collisional regions shown in Fig. 7 represent the flow head, which although wet, is characterised by granular collisions and fluid turbulence. The non-fluctuating regions depict the steady flow body, and the layered collisional and nonfluctuating snapshots represent the head-body transition. Tischer et al. [47] also used PIV velocity data to identify the head-body transition in a series of dry sand avalanche experiments. Surface velocity profiles of a sand flow along a deformable bed showed a distinct head-characterised by fluctuating downstream velocities-and body-characterised by a uniform downstream velocity profile. This bears similarities to the head-body transition identified in our two-phase experiments, and suggests that it would be of value for future studies to investigate the head-body transition using both side (as in the current work) and surface velocity profiles. Tischer et al. [47] also identified the development of distinct head-body architectures for different slope angles. We expect that the slope angle would also affect the transition from collisional to non-fluctuating behaviour in the current experiments, and is something that could be the subject of future studies.

\subsection{Velocity profiles}

The corresponding contour plots for the PIV velocity data are shown in Fig. 8. After the initial, fully collisional region of the flow, there is a concentrated area of high velocity in the lower flow region at $t=0.3 \mathrm{~s}$. Above this, the upper, collisional layer exhibits some negative velocities. These negative values do not represent the true flow velocity, and arise due to there not being a sufficient 

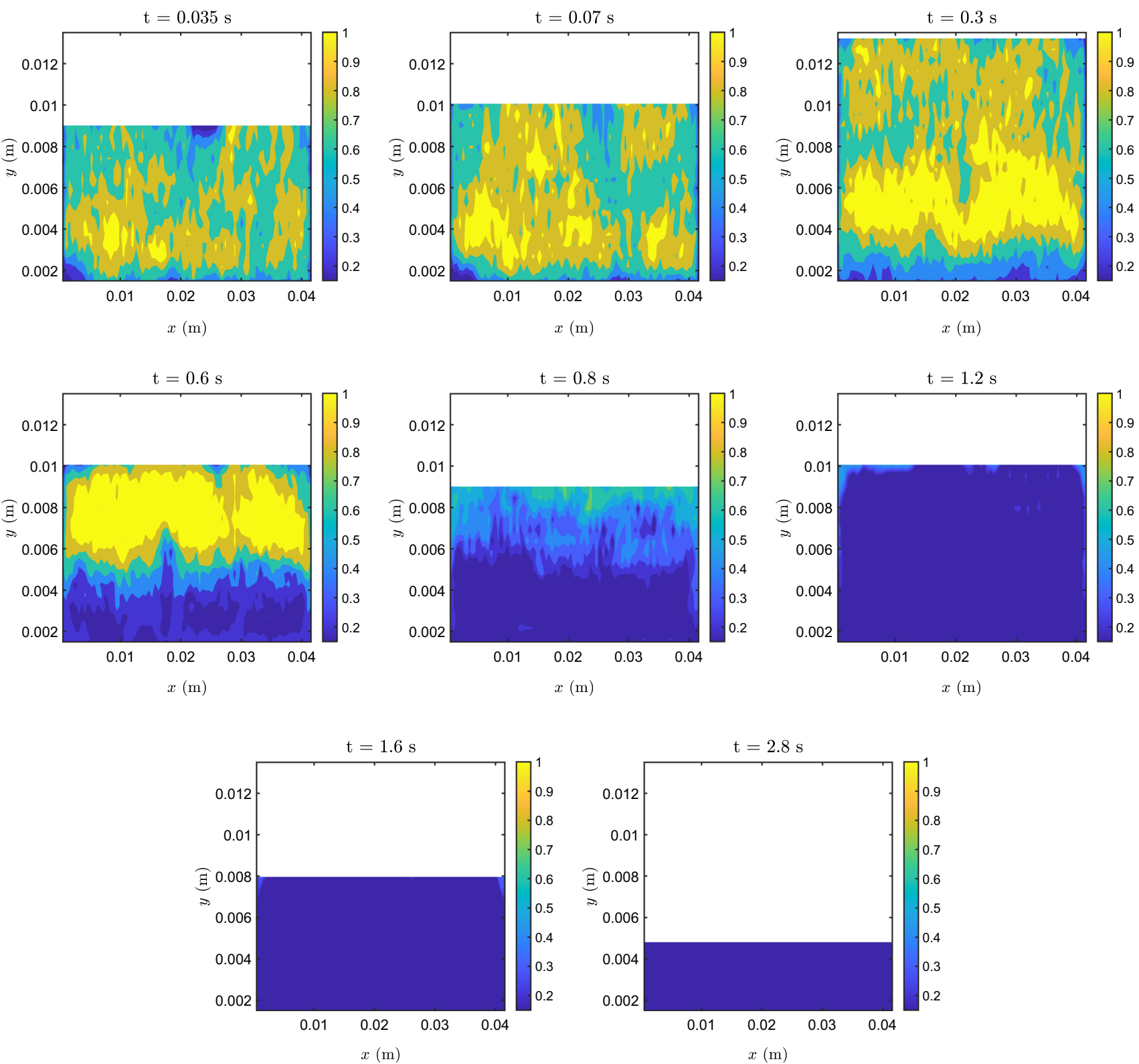

Fig. 6 Contour plots of standard deviation $\bar{e}$ at different times of flow for the experimental water-granular mixture, Run 1 . The lower limit on the scale bar is defined as $\bar{e}=0.15 \mathrm{~m} \mathrm{~s}^{-1}$, which is the suggested cut-off between fluctuating and steady viscous behaviour used in the experiments of Paleo Cageao [34]

correlation between particles in successive frames for the PIV method to produce robust velocity vectors. Although these vectors do not represent the true velocity, they indicate the high turbulence of the flow. By $t=0.6 \mathrm{~s}$ the height of the concentrated, high velocity region has increased. Between times of $t=0.8 \mathrm{~s}$ and $t=1.6 \mathrm{~s}$, the velocity contours are positive everywhere, and show an increase with height from the flume bed up to a maximum region. The velocity values decrease slightly at the free surface. This could be due to the lack of particles detected with the PIV method at the surface, where the snapshots show that there is a very thin watery layer.
Focusing on the presence of a non-fluctuating flow layer, the velocity profiles at different times from $t=0.6$ to $t=2.8 \mathrm{~s}$ are plotted together in Fig. 9a. The height of the velocity maximum increases from $t=0.6 \mathrm{~s}$ to $t=1.2 \mathrm{~s}$, and then consistently decreases until $t=2.8 \mathrm{~s}$. Figure $9 \mathrm{~b}$ shows the normalised velocity and height, obtained by dividing the velocity and the height by the maximum velocity $u_{\max }$ and the flow depth $H$, respectively. With the exception of $t=0.6 \mathrm{~s}$ (which has a considerably lower normalised velocity maximum than the other profiles), the majority of the velocity profiles fall onto a single curve. Although there is some small variation amongst the three 

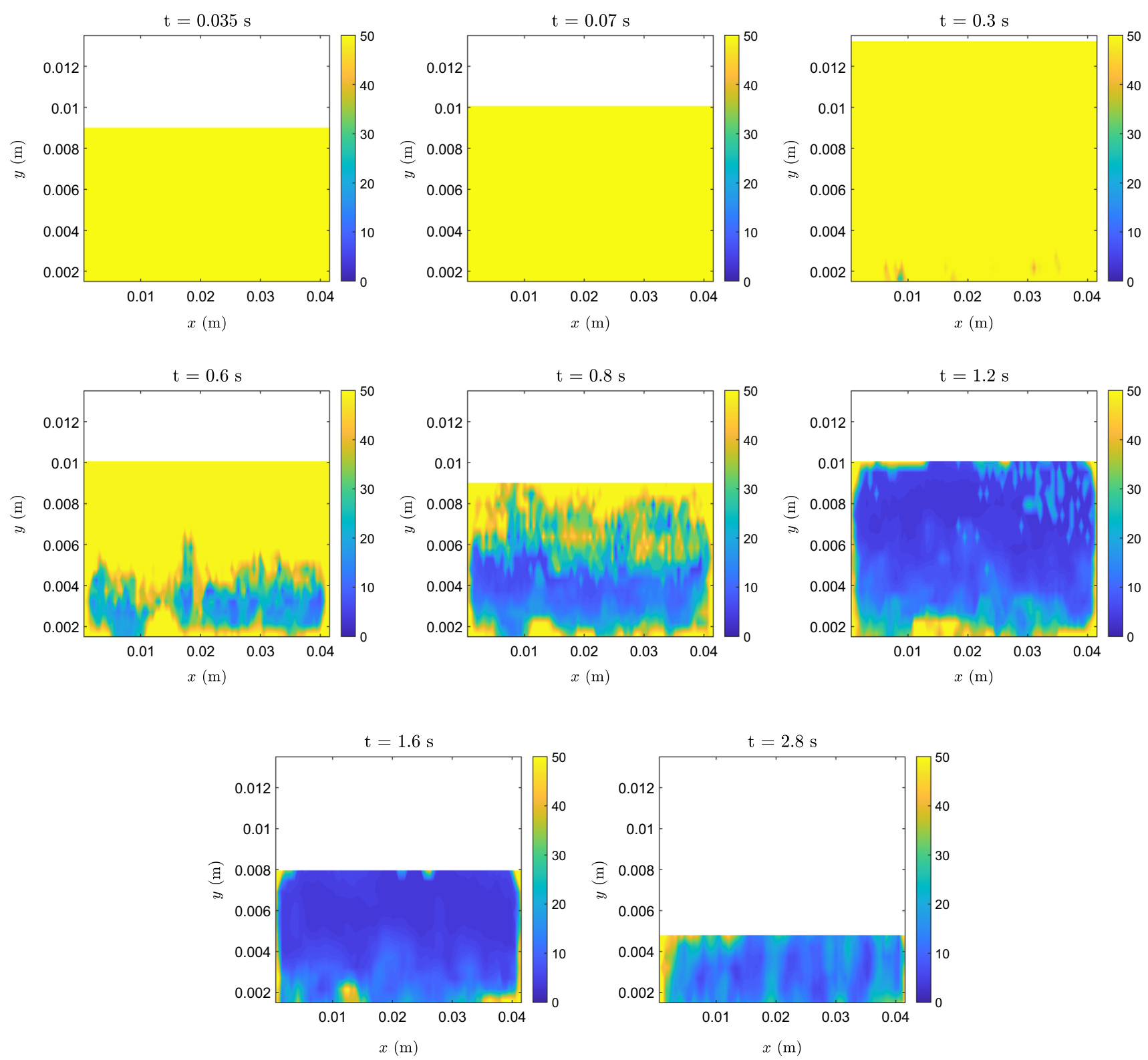

Fig. 7 Contour plots of standard deviation as a percentage of the average velocity $100 \times \bar{e} / \bar{u}_{x}$ at different times of flow for Run 1 of the experiment. The upper limit on the scale bar is defined as $50 \%$ of the velocity average

different runs at certain times, they are consistent in that the velocity profiles between $t=1.2$ and $t=2.4$ are almost indistinguishable from one another. At these times, the velocity increases linearly with height in the region above the flume bed, from a value of approximately zero (at the bed). The velocity gradient increases as the height approaches that of the velocity maximum, which has a nondimensional height of approximately 0.8. Above this height, the velocity decreases slightly towards the surface. The collapse of the profiles onto one indicates the similarity of the flow over this time frame, as also shown in other gravity-driven granular flows, e.g. [3, 26, 41]. The characteristics of experimental flows that are comparable to the current work are summarised in Table 1.

The velocity profiles shown in Fig. 9 are comparable to a selection of results presented in the literature. The profiles in the current work bear a strong resemblance to the solid bed flow profiles first identified by Armanini et al. [3] (see Fig. 10). Similar convex profiles have also been observed in the steady state flow bodies of debris flows in channel [41] and rotating drum [26] experiments.

Our velocity profiles, particularly in the transition region, also share similarities with those observed in the steady state profiles of some submarine gravity currentswhere differences in density drive a dense fluid through a 

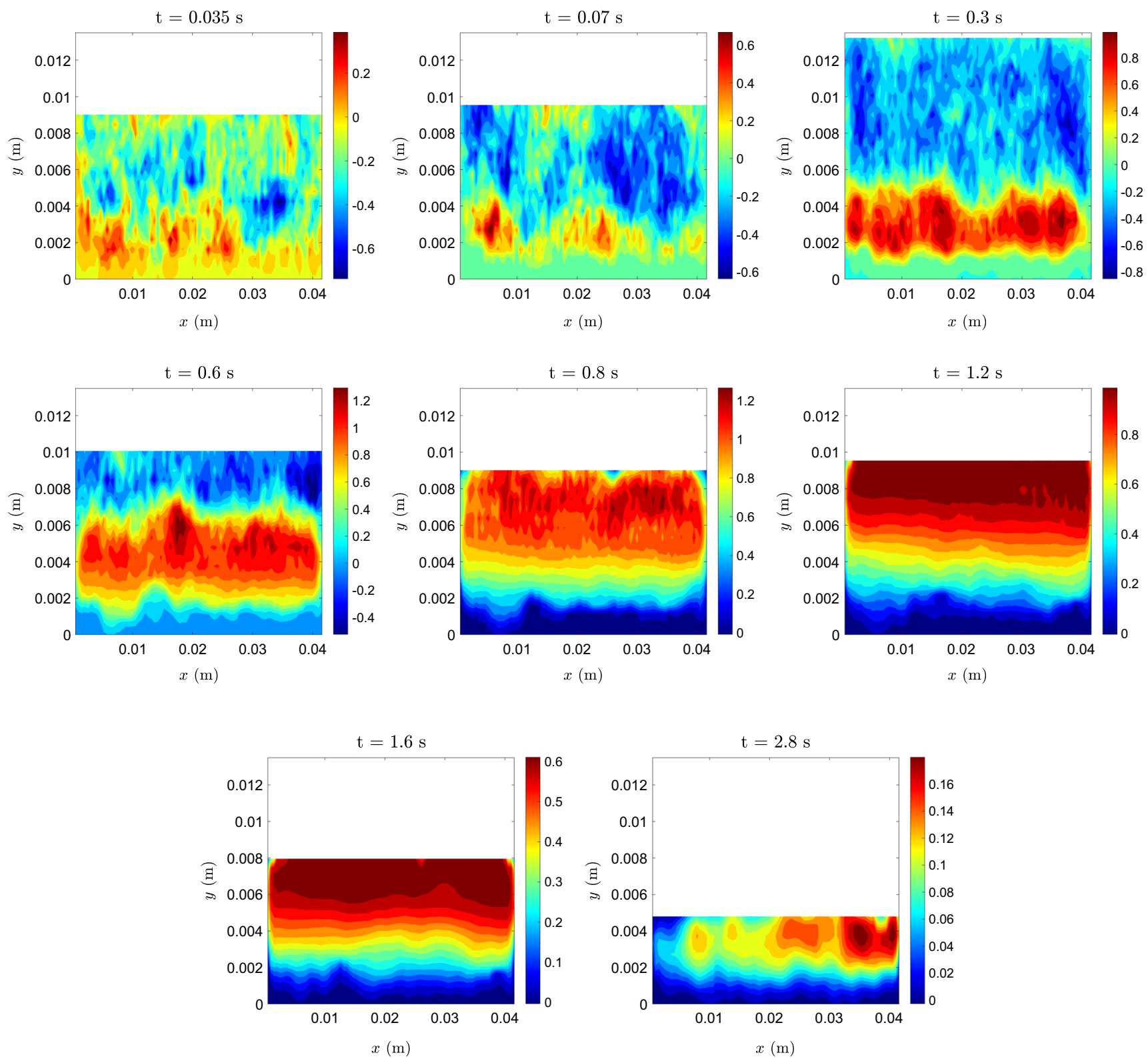

Fig. 8 Contour plots of horizontal velocity $u_{x}\left(\mathrm{~m} \mathrm{~s}^{-1}\right)$ at different times for Run 1 of the experimental debris flow. Note the difference in scale for each image

less dense, ambient fluid [27, 30, 43]. For some sedimentladen flows, notably high concentration turbidity currents, the settling of sediment can result in a layer of high concentration at the bed, while the upward mixing of turbulence produces a dilute upper layer that entrains sediment $[40,44]$. In the internal profiles of these flows, the velocity maximum is located at the top of the lower layer due to the balance of the shear at the bed and at the interface between the dense fluid and the ambient fluid [27]. Such profiles are observed in steady state gravity currents, and above the interface between the two layers of material the velocity steadily approaches a zero value. This overall shape is similar to the internal velocity profiles in the current experimental flow, notably at $t=0.6 \mathrm{~s}$. Although our flow is mostly transient at this time (and exhibits significant fluctuations in the upper layer), the analogy to high concentration turbidity currents provides a deeper understanding of the mechanism responsible for the observed velocity profiles. Furthermore, it has been postulated in the literature that the transport of sediment in high concentration turbidity currents is a result of the interaction between a high concentration lower layer, and a turbulent upper layer [40]. This has potential relevance to the formation of the observed architecture in the current flow. 

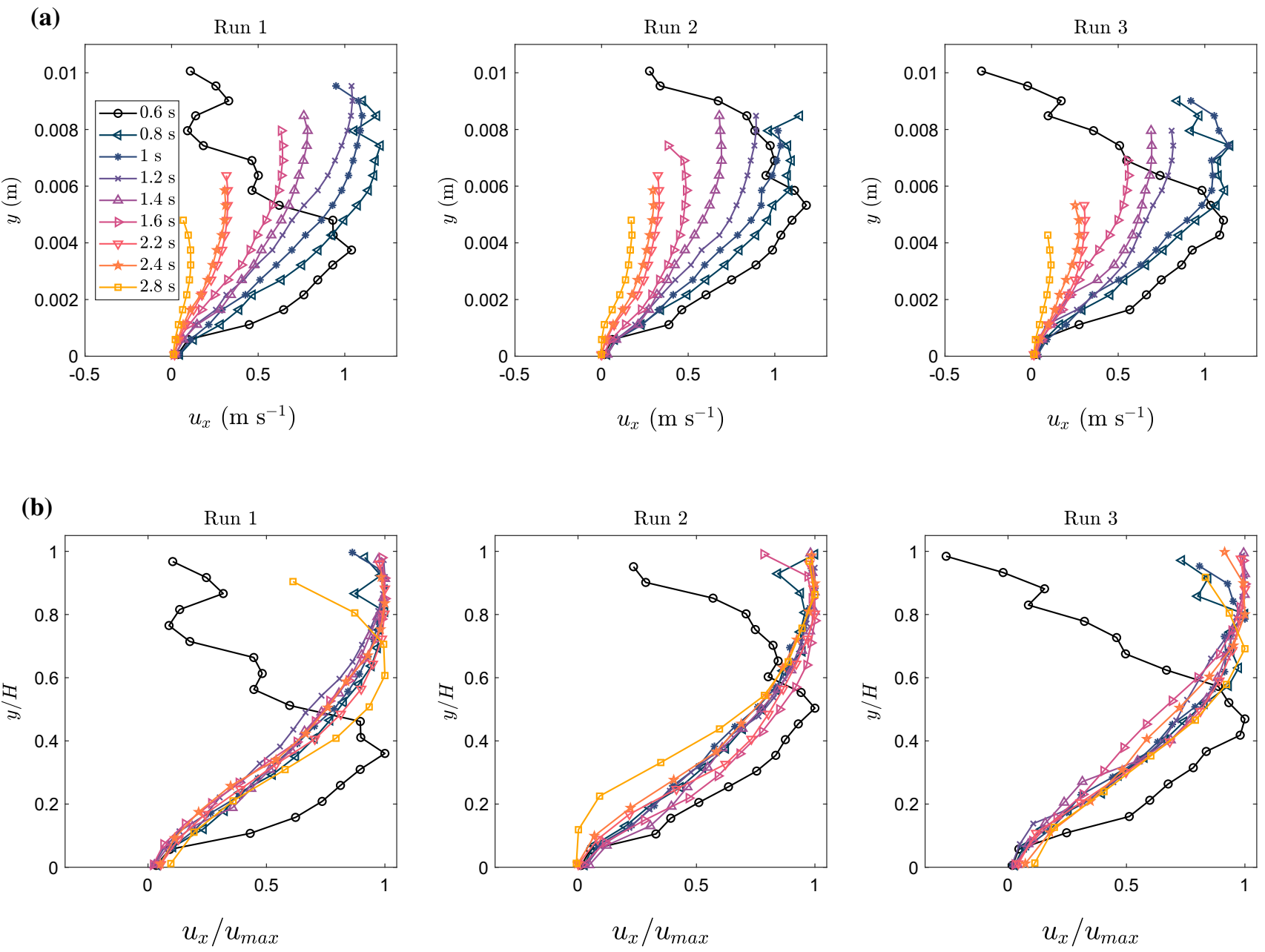

Fig. 9 Plots of a horizontal velocity, and $\mathbf{b}$ normalised horizontal velocity, against height at $x=1.087 \mathrm{~m}$ downstream from the lock gate. On each graph the plotted profiles are from eight different flow times, ranging between $t=0.6 \mathrm{~s}$ and $t=2.8 \mathrm{~s}$, for the three different experimental runs

Table 1 A summary of the relevant experimental parameters in the current work, and selected investigations in the literature

\begin{tabular}{|c|c|c|c|c|c|c|}
\hline References & $\begin{array}{l}\text { Inclination } \theta \\
\left({ }^{\circ}\right)\end{array}$ & $\begin{array}{l}\text { Volume fraction } \\
\phi_{s}\end{array}$ & Granular material & Fluid & $d_{50}(\mathrm{~mm})$ & $C_{U}$ \\
\hline Present work & 31 & 0.44 & Crushed glass grit & Water & 0.917 & 5 \\
\hline Armanini et al. [3] & $5 \leq \theta \leq 22$ & $0.346-0.529$ & PVC pellets & Water & 3.7 & 1 \\
\hline Kaitna et al. [26] & $\mathrm{n} / \mathrm{a}$ & $0.6,0.62,0.7$ & Gravel & Water, mud & $4,8,10,13$ & n.p. \\
\hline Paleo Cageao [34] & 27 & 0.4 & Glass spheres & Water, glycerol & 2 & 1 \\
\hline $\begin{array}{l}\text { Sanvitale and Bowman } \\
\text { [41] }\end{array}$ & 24.5 & 0.7 & $\begin{array}{l}\text { Crushed and subrounded } \\
\text { glass }\end{array}$ & $\begin{array}{l}\text { Hydrocarbon } \\
\text { fluid }\end{array}$ & 7.1 & $3,10,20$ \\
\hline
\end{tabular}

$\theta$ is the flume inclination, $\phi_{s}$ is solid volume fraction, $d_{50}$ is the mean particle size and $C_{U}$ is the coefficient of uniformity. The abbreviation n.p. denotes information that was not provided in the literature

However, it should be noted that two-layer turbidity currents are only a subset of natural systems (e.g. [36]), and many flows are likely to exhibit a more gradual stratification [37].

\subsection{Shear behaviour}

Neglecting the horizontal gradients caused by the vertical velocity $u_{y}$, the local shear strain rate $\dot{\gamma}$ is defined as 
(a)

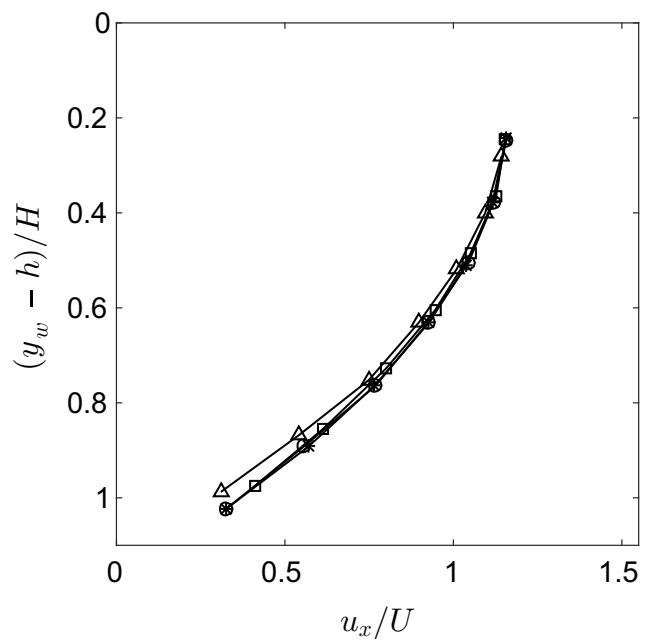

(b)

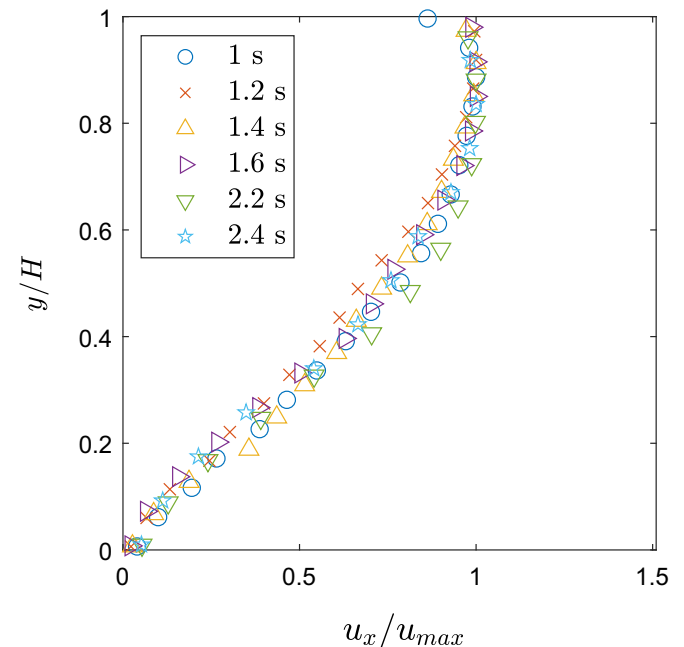

Fig. 10 The normalised internal velocity profiles in the steady, solid bed flow experiments of a Armanini et al. [3] (adapted from Armanini et al. [3]), compared with $\mathbf{b}$ the velocity profiles in the body of the current experiment (Run 1). For the former, plotted on the $x$-axis is horizontal velocity normalised by the mean velocity $U$. The $y$-axis shows $\left(y_{w}-h\right) / H$, where $y_{w}$ is the saturation line (obtained by visual inspection). The points correspond to the experimental velocity values, where the different symbols refer to results from different runs with the bed slope varying from $19^{\circ}-23^{\circ}$. The velocity values near the free surface were not obtained

$\dot{\gamma}=\frac{\partial u_{x}}{\partial y}$

which can be approximated at each vertical height $y_{i}$ as:

$\dot{\gamma}_{i} \approx \frac{u_{x, i+1}-u_{x, i}}{\Delta y}$

where $u_{x, i}$ is the velocity at the current vertical position $y_{i}$, $u_{x, i+1}$ is the velocity at the subsequent height $y_{i+1}$, and $\Delta y$ is the distance separating the vertical sampling points. The profiles of local shear rate plotted against height are shown in Fig. 11a for Run 1 of the experiments at different flow times.

At all times shown, the shear increases with distance from the bed to a maximum value in the lower part of the flow-representing the shear between the coarse flow bed and dense granular material in this region. For $t=0.6$ and $t=0.8 \mathrm{~s}$ the shear fluctuates locally as the profiles exhibit an overall decrease with height, which is most pronounced at the earlier flow time. At the interface between the collisional and non-fluctuating layers at $t=0.6 \mathrm{~s}$ and $t=0.8 \mathrm{~s}$ (see Fig. 7), the shear rate decreases to a large negative value. This is followed by an increase in shear above the interface, highlighting the presence of a shearing layer in this region. The profiles from $t=1 \mathrm{~s}$ onwards exhibit similar behaviour of an increase in shear in the bed region to a maximum value close to the bed, followed by an approximately linear and steep decrease in shear with height toward the free surface. At the surface, the shear tends to a small, negative value due to the fact that the velocity at the surface is slightly lower than the velocity just beneath the surface (which is due to the presence of the thin watery layer).

Following Sanvitale and Bowman [41], the normalised shear rate is obtained by dividing by the depth-averaged shear rate $\overline{\dot{\gamma}}$ :

$\hat{\dot{\gamma}}=\frac{\dot{\gamma}}{\bar{\gamma}}=\frac{\partial u_{x}}{\partial y} \frac{H}{\left(u_{H}-u_{\text {slip }}\right)}$,

where $u_{H}$ and $u_{\text {slip }}$ are the values of horizontal velocity at the free surface and the bed, respectively. Profiles of normalised local shear are provided in Fig. 11b and c, where the latter shows a wider range on the horizontal axis. The fluctuating profile at $t=0.6$-where much of the flow remains in the collisional regime-clearly stands out against the others as having the largest and most variable magnitude of shear. Apart from at $t=2.8 \mathrm{~s}$, the remaining shear rate profiles collapse onto the same shape. The profile at $t=2.8 \mathrm{~s}$-towards the end of the flow-has a much shallower gradient of decreasing shear above the maximum value, and the shear becomes negative in the upper region.

\subsection{Rheological approximation}

Here we utilise the analytical profiles of Bagnold [4]derived from sheared mixtures of suspended, non-cohesive spheres in a viscous fluid-to identify what rheological approximation could represent the steady, non-fluctuating flow body. Bagnold [4] identified two flow regimes-viscous and granular-which were distinguished according to a dimensionless number describing the ratio of internal grain stresses to fluid stresses. Applying Bagnold's findings to a 

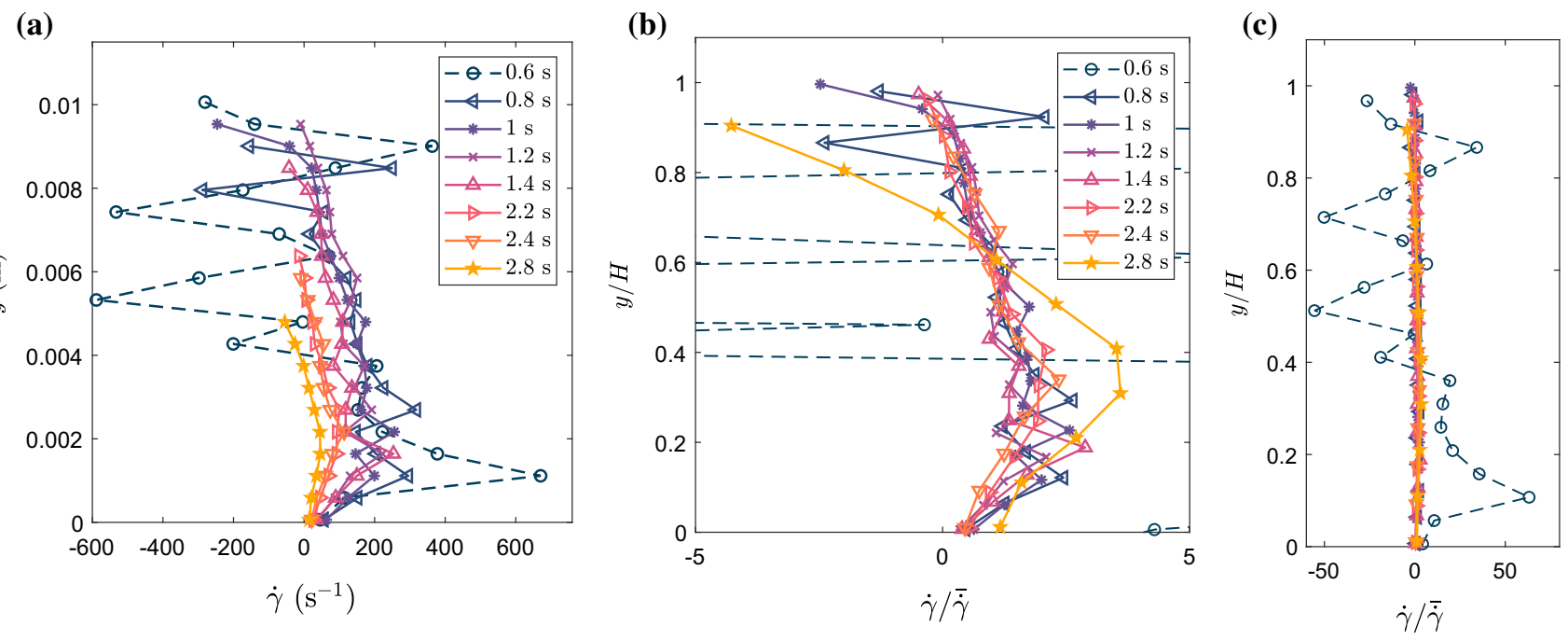

Fig. 11 Plots of $\mathbf{a}$ shear strain rate, $\mathbf{b}$ normalised shear strain rate, and $\mathbf{c}$ normalised shear strain rate with a greater shear range on the horizontal axis against height at $x=1.087 \mathrm{~m}$ downstream from the lock gate, for Run 1 of the experiments

uniform steady flow results in two theoretical vertical velocity profiles. For a viscous-type flow (dominated by viscous forces), the velocity profile scales as $u_{x}(y) \propto H^{2}-(H-y)^{2}$, where $H$ is the height of the free surface. Alternatively, the velocity in a granular regime (dominated by frictional contact) scales as $u_{x}(y) \propto H^{\frac{3}{2}}-(H-y)^{\frac{3}{2}}$.

Figure 12 shows the normalised velocity profiles for Run 1 of the experiments between times $t=1 \mathrm{~s}$ and $t=2.4 \mathrm{~s}$. The closest fit to the experimental results is found with the viscous scaling, which captures the overall velocity shape throughout the shear layer. In the experiments of Sanvitale and Bowman [41], mixtures with a wide grain size distribution (with a coefficient of uniformity of $\left.C_{U}=20\right)$ exhibited a viscous-type velocity profile.

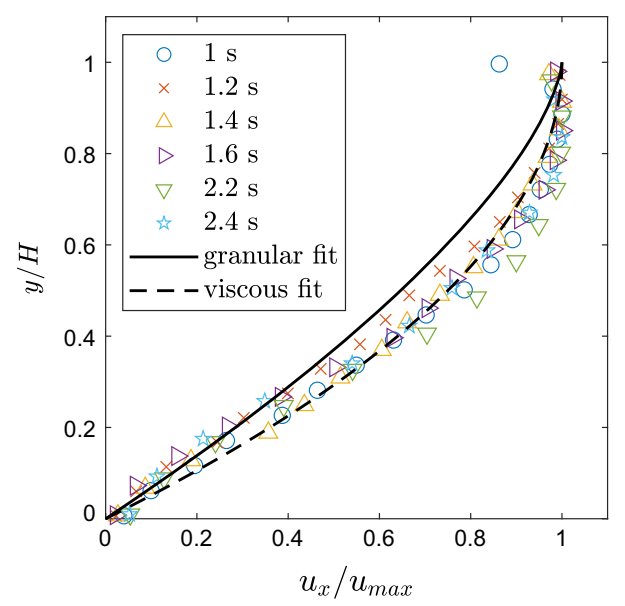

Fig. 12 Normalised velocity profiles in the sheared region for Run 1 of the experimental debris flow, with a best fit granular and viscous scaling. The best fit scaling coefficient is 1 in both cases
Conversely, for $C_{U}=3$ a granular profile provided the best fit to the experimental data. A wider grain size distribution promotes particle segregation, which can lead to the finer particles being trapped within the solid matrix. The presence of these fine grains enhances the viscosity of the interstitial fluid, and viscous forces influence flow behaviour [17]. Conversely, for a more uniform particle distribution, the dominating forces are generally inter-particle frictional contacts. Here, the viscous profile provides the closest fit to the experimental results, despite a relatively small coefficient of uniformity of $C_{U}=5$. This is possibly due to the proportion of very small particles with diameters less than $0.5 \mathrm{~mm}$ that are present within the mixture (see Fig. 2), which add to the fluid viscosity. The results also suggest that the cut-off between granular and viscous-type flow may lie between $C_{U}=3$ and $C_{U}=5$. A suggested area for future work is to perform further experiments with different values of $C_{U}$, to test this hypothesis.

An alternative and perhaps more physically relevant scaling than the viscous and granular-type profiles can be obtained by accounting for strain rate dependence in the rheology of dry granular flows. This is the so-called $\mu(I)$ rheology $[8,16,25]$-the shear stress $\tau$ is proportional to the normal stress $P$ via a shear rate dependent friction coefficient $\mu(I)$ :

$\tau=\mu(I) P$

where $I=\dot{\gamma} d / \sqrt{P / \rho}$ is the inertia number (the ratio of macroscopic shear deformation to inertial granular collisions). By assuming that the stress distribution is isotropic, the following analytical velocity profile can be derived for a dry granular surface flow on an inclined place (see [14] for details): 
$\frac{u_{x}(y)}{\sqrt{g d}}=A(\theta) \frac{\left(H^{3 / 2}-(H-y)^{3 / 2}\right)}{d^{3 / 2}}, A(\theta)=\frac{2}{3} I \sqrt{\cos (\theta)}$.

Note that this is similar to the Bagnold granular-type profile, yet it is derived in a different way and does not require a scaling parameter. It is instead a function of the local flow strain rate through the inertia number.

Although derived for a dry granular flow, (6) is applicable to the current work where granular interactions are significant. Figure 13 compares the experimental velocity profiles with those derived from the $\mu(I)$ rheology. The latter are a function of the experimental values of shear strain rate, where we have used the full shear profiles as opposed to a single depth-averaged value. It can be seen that the analytical velocity profiles closely match the experimental values in the lower part of the flow, where the granular material is most dense and shearing is greatest. The analytical profiles diverge from the actual values toward the free surface, where the former tend to a negative value. This is not physical for an inclined surface flow and is likely an artefact of the shear behaviour of the experiments, which in turn is a result of the complex coupling between the solid and fluid phases where the upper part of the flow tends to be more dilute. These results suggest that shear rate dependence of the granular phase is dominant in the lower part of the experimental flow, yet the upper part is likely more influenced by fluid forces, which are not included in the $\mu(I)$ rheology theory. A rheological model that incorporates fluid stresses and grain-fluid interactions, in addition to granular contacts and shear rate dependence, is therefore required to accurately capture the coupled behaviour observed in the experimental debris flow.

\subsection{Commentary on debris flow architecture and fluid-particle interaction}

In the field, subaerial debris flows are typically composed of a dry head containing large particles, where the dynamics are dominated by granular collisions and frictional forces. Behind the head, the flow body contains smaller particles and interstitial fluid and exhibits fluid-like behaviour [17, 32]. The head-body architecture is attributed to complex couplings related to the grain size distribution, material fines content and pore water pressures $[21,23]$. It has also been observed in small scale experiments [26, 35, 41], including those with monodispersed spherical mixtures [34]. In the current work, the high water content of the experimental mixture $\left(\phi_{s}=0.44\right)$ does not permit the formation of a dry, granular head. In fact, the flow remains fully saturated for its duration. The front of the flow is still dominated partly by granular collisions, yet fluid turbulence also governs the behaviour in this region. It should be noted that in the current work we have focused on the initial stages of flow development, having identified the two-layer transition region between the dilute flow head and body. We suspect that, for the same experimental conditions in a much longer flume, the front of the flow would eventually become dry.

Our experiments exhibit a unique type of head-body transition, while still retaining similarities to other classic gravity-driven flows (such as dry granular avalanches [47], two-phase solid bed flows [3], and viscous-type granular flow regimes [41]). Our experiments differ from classic two-phase debris flow experiments in that the flow head consists of a mixture of dilated granular material and water, as opposed to a dry granular front. This may be important when applying models derived from subaerial debris flows to subaqueous debris flows (e.g. [11-13, 36]), which have wet heads. The results from our experiments suggest that subaqueous debris flows may exhibit markedly different
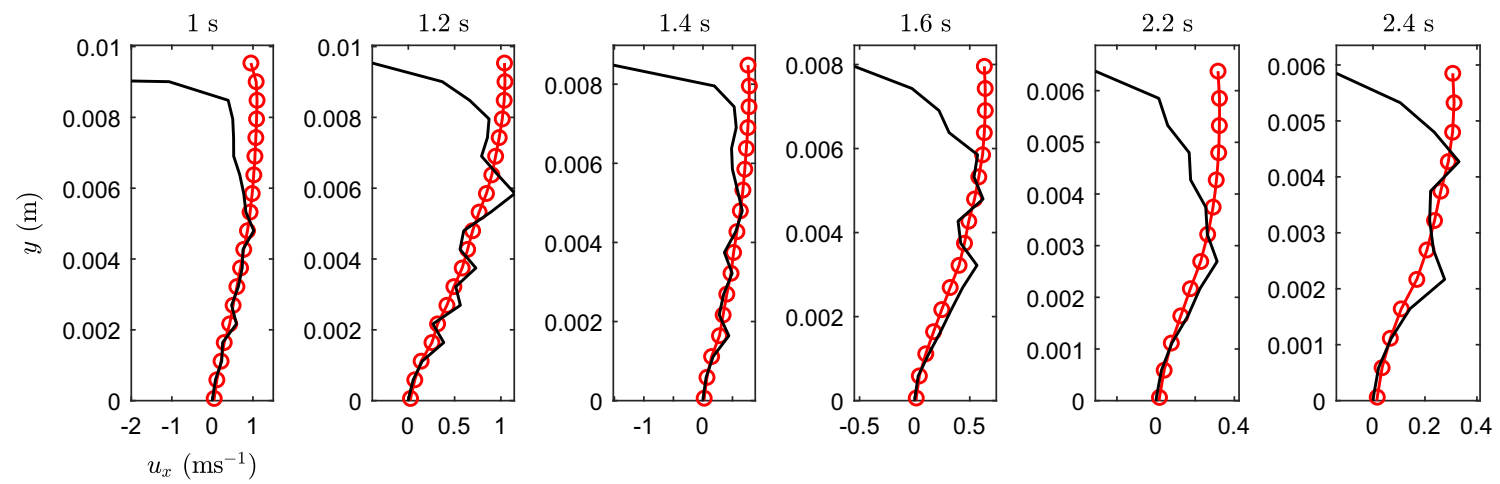

Fig. 13 Velocity profiles in the sheared region for Run 1 of the experimental debris flow (red dots), plotted against the profiles derived from the $\mu(I)$ rheology of GDR MiDi group [14] (black lines). The following parameters were used to obtain the profiles: $d=d_{50}=0.00917 \mathrm{~m}, \rho=1373$ $\mathrm{kg} \mathrm{m}^{-3}, \theta=31^{\circ}, P=\rho g(H-y) \cos \theta \mathrm{Pa}$. (colour figure online) 
flow behaviour at the head, compared to predictions from current models derived from subaerial debris flows. Existing subaerial debris flow models, with dry heads, predict that the head has a higher shear strength than the body as it lacks the elevated pore pressures, and deposition is frictionally dominated at the leading edges of the flow $[17,21,31]$.

In the literature, the majority of debris flow experiments involve a considerably lower volume fraction of fluid than we have used here. In one of their series of experiments, Paleo Cageao [34] used a similar solid-fluid ratio $\left(\phi_{s}=0.4\right)$ to that of the current work. However, as opposed to the current work, their flow exhibited a dry, granular front at a distance $0.232 \mathrm{~m}$ downstream from the lock gate, while the tail of their flow consisted entirely of water, suggesting a lack of solid-fluid coupling. As can be seen from Table 1, the experimental parameters of our experiments and those of [34] are comparable, with the exception of the granular material-we used angular particles, while they used glass spheres. This is the key factor behind the stark difference in behaviour between our experiments and those of Paleo Cageao [34]. Realistic, angular material allows for the interlocking of grains and inter-particle shearing, which adds extra frictional resistance and a lower permeability than idealised spheres. The dilation and contraction of the crushed particles also regulates the motion of the interstitial water, enhancing the coupling between the two phases. Solid-fluid coupling is far weaker in spherical mixtures than realistic granular material, which has a significant effect on flow dynamics [17].

\section{Conclusions}

The internal observations of an evolving experimental debris flow have provided valuable insight into the complex interaction between propagating particulate and water phases. The experiments consisted of a relatively dilute granular material $\left(\phi_{s}=0.44\right)$, which exhibited a spatial and temporal evolution from a transient, turbulent front to a steady flow body. PIV was used to produce robust velocity vectors, which could provide valuable validation for the development of new two-phase numerical models. The transition from the collisional flow front to the non-fluctuating body has been quantified for the first time by considering the deviations of velocity as a percentage of the local average velocity at each time frame. One of the most striking features of this head-body transition is the presence of two distinct shearing layers-a non-fluctuating lower layer, and a collisional upper layer. Unlike similar experiments with monosized spheres [34], the body of the current flow exhibited a thin layer of water overlying the viscous mixture for the entirety of the flow duration. This indicates that the behaviour of the flow was influenced strongly by the coupling of the granular and liquid constituents. Indeed, in reality granular-fluid coupling plays a vital role in debris flow dynamics [18, 22]. Regarding the non-fluctuating flow body, a viscous-type rheology was able to capture the velocity throughout the majority of its depth. The granular material in our experiments had a coefficient of uniformity $C_{U}$ of 5 . Comparison to the experiments of Sanvitale and Bowman [41] suggests that the transition from a granular to a viscous-type flow profile takes place between a coefficient of uniformity of 3 and 5 . Further work investigating the effect of particle size distribution on granular and viscous scaling is recommended. The experimental velocity profiles were also captured well in the lower region by the strain rate-dependent $\mu(I)$ profile, yet not in the uppermost part of the flow, which reflects the need to properly include grain-fluid coupling effects in rheological models of two-phase flows. On a final note, our results have raised a question regarding the validity of some current models of subaqueous debris flows that are based on subaerial flow observations, which should should be investigated further.

Acknowledgements This work was supported by the Engineering and Physical Sciences Research Council (EPSRC) Centre for Doctoral Training in Fluid Dynamics at the University of Leeds under Grant No. EP/L01615X/1. The experiments were conducted in the NERC recognized Sorby Environmental Fluid Dynamics Laboratory at the University of Leeds. We thank Helena Brown and Rob Thomas for their invaluable help with the execution of the experiments, and Georgina Williams for her expertise on the PIV methodology. Finally, we thank Wei $\mathrm{Wu}$ and the two anonymous reviewers for their helpful comments which greatly improved the manuscript.

\section{Declarations}

Conflict of interest The authors declare that they have no conflict of interest.

Open Access This article is licensed under a Creative Commons Attribution 4.0 International License, which permits use, sharing, adaptation, distribution and reproduction in any medium or format, as long as you give appropriate credit to the original author(s) and the source, provide a link to the Creative Commons licence, and indicate if changes were made. The images or other third party material in this article are included in the article's Creative Commons licence, unless indicated otherwise in a credit line to the material. If material is not included in the article's Creative Commons licence and your intended use is not permitted by statutory regulation or exceeds the permitted use, you will need to obtain permission directly from the copyright holder. To view a copy of this licence, visit http://creativecommons. org/licenses/by/4.0/.

\section{References}

1. Adrian RJ (1991) Particle-imaging techniques for experimental fluid mechanics. Annu Rev Fluid Mech 23(1):261-304 
2. Adrian RJ, Westerweel J (2011) Particle image velocimetry. Cambridge University Press

3. Armanini A, Capart H, Fraccarollo L, Larcher M (2005) Rheological stratification in experimental free-surface flows of granular-liquid mixtures. J Fluid Mech 532:269-319

4. Bagnold RA (1954) Experiments on the gravity-free dispersion of large solid spheres in a Newtonian fluid under shear (1954). In: The physics of sediment transport by wind and water. ASCE, pp 114-129

5. Barla G, Paronuzzi P (2013) The 1963 vajont landslide: 50th anniversary. Rock Mech Rock Eng 46(6):1267-1270

6. Costa JE (1984) Physical geomorphology of debris flows. In: Developments and applications of geomorphology. Springer, pp 268-317

7. Cui P, Zeng C, Lei Y (2015) Experimental analysis on the impact force of viscous debris flow. Earth Surf Proc Land 40(12):1644-1655

8. Da Cruz F, Emam S, Prochnow M, Roux J-N, Chevoir F (2005) Rheophysics of dense granular materials: discrete simulation of plane shear flows. Phys Rev E 72(2):021309

9. Dantec Dynamics (2018) DynamicStudio user manual

10. de Haas T, Braat L, Leuven JR, Lokhorst IR, Kleinhans MG (2015) Effects of debris flow composition on runout, depositional mechanisms, and deposit morphology in laboratory experiments. J Geophys Res Earth Surf 120(9):1949-1972

11. Ducassou E, Migeon S, Capotondi L, Mascle J (2013) Run-out distance and erosion of debris-flows in the Nile deep-sea fan system: evidence from lithofacies and micropalaeontological analyses. Mar Pet Geol 39(1):102-123

12. Felix M, Peakall J (2006) Transformation of debris flows into turbidity currents: mechanisms inferred from laboratory experiments. Sedimentology 53(1):107-123

13. Felix M, Leszczyński S, Ślączka A, Uchman A, Amy L, Peakall J (2009) Field expressions of the transformation of debris flows into turbidity currents, with examples from the Polish Carpathians and the French Maritime Alps. Mar Pet Geol 26(10):2011-2020

14. GDR MiDi Group (2004) On dense granular flows. Eur Phys J E 14(4):341-365

15. Gregoretti C (2000) The initiation of debris flow at high slopes: experimental results. J Hydraul Res 38(2):83-88

16. Iordanoff I, Khonsari M (2004) Granular lubrication: toward an understanding of the transition between kinetic and quasi-fluid regime. ASME J Tribol 126(1):137-145

17. Iverson RM (1997) The physics of debris flows. Rev Geophys 35(3):245-296

18. Iverson RM (2003) The debris-flow rheology myth. In: Debrisflow hazards mitigation: mechanics, prediction, and assessment, vol 1. Millpress, pp 303-314

19. Iverson RM (2015) Scaling and design of landslide and debrisflow experiments. Geomorphology

20. Iverson RM, George DL (2014) A depth-averaged debris-flow model that includes the effects of evolving dilatancy. i. physical basis. Proc R Soc A Math Phys Eng Sci 470(2170):1

21. Iverson RM, Logan M, LaHusen RG, Berti M (2010) The perfect debris flow? Aggregated results from 28 large-scale experiments. J Geophys Res Earth Surf 115(F3)

22. Iverson RM, Reid ME, Logan M, LaHusen RG, Godt JW, Griswold JP (2011) Positive feedback and momentum growth during debris-flow entrainment of wet bed sediment. Nat Geosci 4(2):116-121

23. Johnson CG, Kokelaar BP, Iverson RM, Logan M, LaHusen RG, Gray JMNT (2012) Grain-size segregation and levee formation in geophysical mass flows. J Geophys Res Earth Surf 117(F1)
24. Johnson PC, Jackson R (1987) Frictional-collisional constitutive relations for granular materials, with application to plane shearing. J Fluid Mech 176:67-93

25. Jop P, Forterre Y, Pouliquen O (2006) A constitutive law for dense granular flows. Nature 441(7094):727-730

26. Kaitna R, Dietrich WE, Hsu L (2014) Surface slopes, velocity profiles and fluid pressure in coarse-grained debris flows saturated with water and mud. J Fluid Mech 741:377-403

27. Kneller BC, Bennett SJ, McCaffrey WD (1999) Velocity structure, turbulence and fluid stresses in experimental gravity currents. J Geophys Res Oceans 104(C3):5381-5391

28. Lanzoni S, Gregoretti C, Stancanelli LM (2017) Coarse-grained debris flow dynamics on erodible beds. J Geophys Res Earth Surf 122(3):592-614

29. Larcher M, Fraccarollo L, Armanini A, Capart H (2007) Set of measurement data from flume experiments on steady uniform debris flows. J Hydraul Res 45(sup1):59-71

30. Lowe RJ, Linden PF, Rottman JW (2002) A laboratory study of the velocity structure in an intrusive gravity current. J Fluid Mech 456:33-48

31. Major JJ, Iverson RM (1999) Debris-flow deposition: effects of pore-fluid pressure and friction concentrated at flow margins. Geol Soc Am Bull 111(10):1424-1434

32. McArdell BW, Bartelt P, Kowalski J (2007) Field observations of basal forces and fluid pore pressure in a debris flow. Geophys Res Lett 34(7):L07406. https://doi.org/10.1029/2006GL029183

33. McKenna JP, Santi PM, Amblard X, Negri J (2012) Effects of soil-engineering properties on the failure mode of shallow landslides. Landslides 9(2):215-228

34. Paleo Cageao P (2014) Fluid-particle interaction in geophysical flows: debris flow. $\mathrm{PhD}$ thesis, University of Nottingham

35. Parsons JD, Whipple KX, Simoni A (2001) Experimental study of the grain-flow, fluid-mud transition in debris flows. J Geol 109(4):427-447

36. Paull CK, Talling PJ, Maier KL, Parsons D, Xu J, Caress DW, Gwiazda R, Lundsten EM, Anderson K, Barry JP et al (2018) Powerful turbidity currents driven by dense basal layers. Nat Commun 9(1):4114

37. Peakall J, Sumner EJ (2015) Submarine channel flow processes and deposits: a process-product perspective. Geomorphology 244:95-120

38. Petley D (2012) Global patterns of loss of life from landslides. Geology 40(10):927-930

39. Pinyol NM, Alvarado M (2017) Novel analysis for large strains based on particle image velocimetry. Can Geotech J 54(7):933-944

40. Postma G, Nemec W, Kleinspehn KL (1988) Large floating clasts in turbidites: a mechanism for their emplacement. Sed Geol 58(1):47-61

41. Sanvitale N, Bowman ET (2017) Visualization of dominant stress-transfer mechanisms in experimental debris flows of different particle-size distribution. Can Geotech J 54(2):258-269

42. Schuster RL, Fleming RW (1986) Economic losses and fatalities due to landslides. Bull Assoc Eng Geologists 23(1):11-28

43. Simpson JE, Britter RE (1979) The dynamics of the head of a gravity current advancing over a horizontal surface. J Fluid Mech 94(3):477-495

44. Stevenson CJ, Feldens P, Georgiopoulou A, Schönke M, Krastel S, Piper DJW, Lindhorst K, Mosher D (2018) Reconstructing the sediment concentration of a giant submarine gravity flow. Nat Commun 9(1):2616

45. Takahashi $\mathrm{T}$ (1978) Mechanical characteristics of debris flow. J Hydraulics Div 104(8):1153-1169

46. Takahashi T (1981) Debris flow. Annu Rev Fluid Mech 13(1):57-77 
47. Tischer M, Bursik MI, Pitman EB (2001) Kinematics of sand avalanches using particle-image velocimetry. J Sediment Res 71(3):355-364

48. Turnbull B, Bowman ET, McElwaine JN (2015) Debris flows: experiments and modelling. CR Phys 16(1):86-96
49. White DJ, Take WA, Bolton MD (2003) Soil deformation measurement using particle image velocimetry (piv) and photogrammetry. Geotechnique 53(7):619-631

Publisher's Note Springer Nature remains neutral with regard to jurisdictional claims in published maps and institutional affiliations. 